\begin{tabular}{|c|c|}
\hline Title & Monitoring of Echinococcus multilocularis infection in red foxes in Shiretoko, Japan, by coproantigen detection \\
\hline Author(s) & NONAKA, N.; TSUKA DA, H.; ABE, N.; OKU, Y.; KAMIYA, M. \\
\hline Citation & $\begin{array}{l}\text { Parasitology, 117, } 193-200 \\
\text { https://doi.org/10.1017/S0031182098002844 }\end{array}$ \\
\hline Issue Date & 1998 \\
\hline Doc URL & http:/hdl .handle.net/2115/7392 \\
\hline Rights & Copyright $\odot 1998$ Cambridge University Press \\
\hline Type & article \\
\hline File Information & Parasitology117.pdf \\
\hline
\end{tabular}

Instructions for use 


\title{
Monitoring of Echinococcus multilocularis infection in red foxes in Shiretoko, Japan, by coproantigen detection
}

\author{
N. NONAKA ${ }^{1 *}, H . T_{\text {TUADA }}^{2}$, N. ABE ${ }^{1}$, Y. OKU ${ }^{1}$ and M. KAMIYA ${ }^{1}$ \\ ${ }^{1}$ Laboratory of Parasitology, Department of Disease Control, Graduate School of Veterinary Medicine, \\ Hokkaido University, Sapporo 060, Japan \\ ${ }^{2}$ Department of Humanities and Human Sciences, Faculty of Letters, Hokkaido University, Sapporo 060, Fapan
}

(Received 28 Fuly 1997 ; revised 27 December 1997 and 28 February 1998; accepted 28 February 1998)

SUMMARY

The study was conducted to evaluate a mAb-based coproantigen detection assay for monitoring fox prevalence of Echinococcus multilocularis infections in the Shiretoko National Park in Hokkaido, Japan. Eight fox families, each consisting of 2-4 adults and their pups, were selected because their territories have been determined. Faeces of each family (total $n=537$ ) were collected monthly from April to October, 1994. Detection of coproantigen and taeniid eggs was recognized in 58 and 27 faeces, respectively, but mostly restricted in 1 family, in which coproantigen ELISA OD values had dual peaks, one in June and the other in October, whereas taeniid eggs were detected only from April to July. Fox pup faeces $(n=51)$ collected around the dens used by the positive family were all coproantigen and taeniid egg negative except for 1 faeces. These results suggest that the prevalence and infection pressure in the study area were low and the infected family terminated the infection in the summer and acquired a new one in the early autumn, 1994. This monitoring method for fox infection will be a practical management tool for E. multilocularis infection, especially at the tourist spots in Hokkaido where close contact of fox with humans is frequently observed.

Key words: Echinococcus multilocularis, coproantigen, red fox, Vulpes vulpes, Japan, diagnosis.

\section{INTRODUCTION}

Echinococcus multilocularis is the causative agent of human alveolar echinococcosis and is distributed widely in the northern hemisphere including Hokkaido, Japan. The cestode is mainly maintained in wild animals, the adult parasitizing foxes and other canids, and the larva in rodents. Its maintenance in wildlife is closely associated with host ecology. Understanding of the epidemiology of the cestode infection in wildlife is, therefore, extremely important to establish reliable preventive measures for human infection. Diagnosis of the definitive hosts, such as foxes, has been carried out by the necropsy of the dead animals (Craig, Rogan \& Allan, 1996). The method is reliable but inappropriate for evaluation of live animals. Faecal examination for parasite eggs is an alternative common method for pre-mortem diagnosis, however, it is not appropriate for specific diagnosis of Echinococcus infection because of the morphological similarities between Echinococcus and other taeniid eggs. Because reliable pre-mortem diagnostic methods for wild canids infected with E. multilocularis have not been available, there is a shortage of some basic epidemiological

* Corresponding author: Laboratory of Parasitology, Department of Disease Control, Graduate School of Veterinary Medicine, Hokkaido University, Sapporo 060, Japan. Tel: +81 11706 5196. Fax: +81 117177569 . Email:nnonaka@vetmed.hokudai.ac.jp information such as seasonal and annual change in infection status in foxes, geographical and temporal distribution of infected foxes, effect on prevalence after preventive treatment etc., all of which will be fundamentally necessary to evaluate risk factors and control measures.

Recently, molecular approaches for specific diagnosis have been widely discussed for Echinococcus infections (Deplazes \& Eckert, 1996; Fraser \& Craig, 1997). Specific DNA amplification from E. multilocularis eggs was reported and shown to be highly sensitive (Bretagne et al. 1993). The technique could be made more sensitive and specific by concentrating eggs and performed more safely by using heatsterilized or deep-frozen eggs (Deplazes \& Eckert, 1996; Yagi et al. 1996b). Therefore, specific DNA amplification has a great potential for the specific diagnosis. Nevertheless, the technique is at present somewhat complicated and contamination problems due to the extreme sensitivity need to be overcome for widespread application. Coproantigen detection techniques have been reported for various parasitic infections including those caused by Echinococcus, Taenia, Hymenolepis (Allan \& Craig, 1989; Allan et al. 1992). Those techniques are easily manipulated and detect specific parasite products such as breakdown products of proglottids or excretory/secretory antigens in the host faeces, thus enabling genus/ species-specific pre-mortem diagnosis. Therefore, coproantigen detection assays would be a practical 
tool for epidemiological studies of the definitive hosts of Echinococcus. A mAb-based coproantigen detection assay has been developed in our laboratory. An actual field evaluation of the assay sensitivity and specificity is now being undertaken but an experimental infection study showed the detection limit in the parasite burden of the assay may be around 100 E. multilocularis infections (Nonaka et al. $1996 a$ ) and the mAb used in the assay scarcely crossreacted with various parasite antigens including taeniid cestodes such as Taenia taeniaeformis, T. crassiceps, and T. hydatigena (Kohno et al. 1995) but reacted with a coproantigen of E. granulosusinfected dogs (Sakai et al. 1995). Another advantage is that the method could detect a heat-resistant, formalin-fixed antigen, leading to safe manipulation of the diagnosis or epidemiological survey (Sakashita et al. 1995).

At tourist locations in Hokkaido, Japan, it has been frequently observed that red foxes (Vulpes vulpes schrencki) contact humans to obtain food. Those foxes set their territories around the tourist areas and thus the same foxes or families contact to humans every year at the same location (Tsukada, 1995, 1997). Therefore, some of those areas could be high risk areas for transmission of the disease to humans. Because of the ease of deworming and monitoring the change in infection status, those locations could be appropriate pilot areas for a trial study of control procedures against the definitive host of the cestode. This field study was conducted to evaluate the coproantigen detection technique for monitoring fox prevalence in one of the tourist areas, Shiretoko National Park in Hokkaido, Japan.

\section{MATERIALS AND METHODS}

\section{Study area}

The field study was conducted along the Shiretoko Park Road in the Shiretoko National Park, Hokkaido, Japan (Fig. 1). In Shiretoko, an intensive radiotelemetry study to determine fox (Vulpes vulpes schrencki) home ranges was carried out from 1992 to 1994 (Tsukada, 1994, 1997) and revealed that 8 families (Family $\mathrm{A}-\mathrm{H}$ ) have their distinct territories along the road (Fig. 2). The family density of the study area $(2 \mathrm{~km} \times 13 \mathrm{~km})$ was estimated to be 0.31 families $/ \mathrm{km}^{2}$ and each family consists of 2-4 adults and their pups. From May to August, foxes were territorial and showed exclusive distribution in their territories, defence against intruding foxes at the edge of territories and site-specific dominance over intruding foxes. From September to April, some foxes moved away from their territories to obtain spatially concentrated foods such as spawned salmon (in autumn) and human food (in winter) but their territories were used intensively by the resident foxes even in this period. It has been observed that some of the foxes in each family come out to the road and wait for tourists to give food (Tsukada \& Nonaka, 1996). Deposits of fox faeces were recognized elsewhere along the road.

\section{Sample collection and process}

It was reported that foxes deposited their faeces inside their territories (Macdonald, 1979, 1980) but the border of adjacent territories in the study area slightly changed depending on seasonal factors (Tsukada, 1997); territories were subclassified into main territory zones of 1 fox family and border territory zones of 2 adjacent fox territories (Fig. 2). The territory of Family D was assumed to be expanded toward the territory of Family $\mathrm{C}$ during the study period, due to the serious injury and consequent death of the male fox in Family $\mathrm{C}$ during May to July.

Once a month from April to October, 1994, all fox faeces deposited in each territory zone (along the Shiretoko Park Road) were collected for investigation of the parasite infection. Fox faeces were distinguished from that of dogs and small mustelids by size and shape and from that of raccoon dogs (Nyctereutes procyonoides albus) which tend to deposit their faeces in a latrine, unlike foxes. In June and July, faeces were also collected around fox dens and a resting site used by the 2 families (Family A and D). In addition, if deposits of faeces by identified foxes having ear tags were observed by chance, they were immediately collected and processed.

The faeces were carefully put into $100 \mathrm{ml}$ polypropylene tubes, soaked with water containing $1 \%$ formalin and $0.3 \%$ Tween 20 and sterilized by incubation at $70^{\circ} \mathrm{C}$ for $12 \mathrm{~h}$. After sterilization, faecal suspensions containing $0.5 \mathrm{~g}$ of faeces were aliquoted into $15 \mathrm{ml}$ centrifuge tubes and $1 \%$ formalin and $0.3 \%$ Tween 20 in water were added to the final volume of $15 \mathrm{ml}$. Then the faecal suspensions were centrifuged at $1000 \mathrm{~g}$ for $10 \mathrm{~min}$ and the supernatant fraction was used for the coproantigen detection assay. The sediments were used for parasite egg examination.

\section{Coproantigen detection assay}

Coproantigen detection was performed by a sandwich enzyme-linked immunosorbent assay (ELISA) as described previously (Nonaka et al. 1996b) using a mAb, EmA9 raised against E. multilocularis somatic antigen (Kohno et al. 1995). A diagnostic cut-off value for the coproantigen detection assay to discriminate between positive and negative values was previously determined by performing the assay on faeces collected from 37 foxes reared at a commercial breeder (Kaji Mink, Fukagawa). The cut-off value, mean plus 3 standard deviations of ELISA OD values of the 37 samples was calculated to be 0.091 (Nonaka et al. 1996a). 


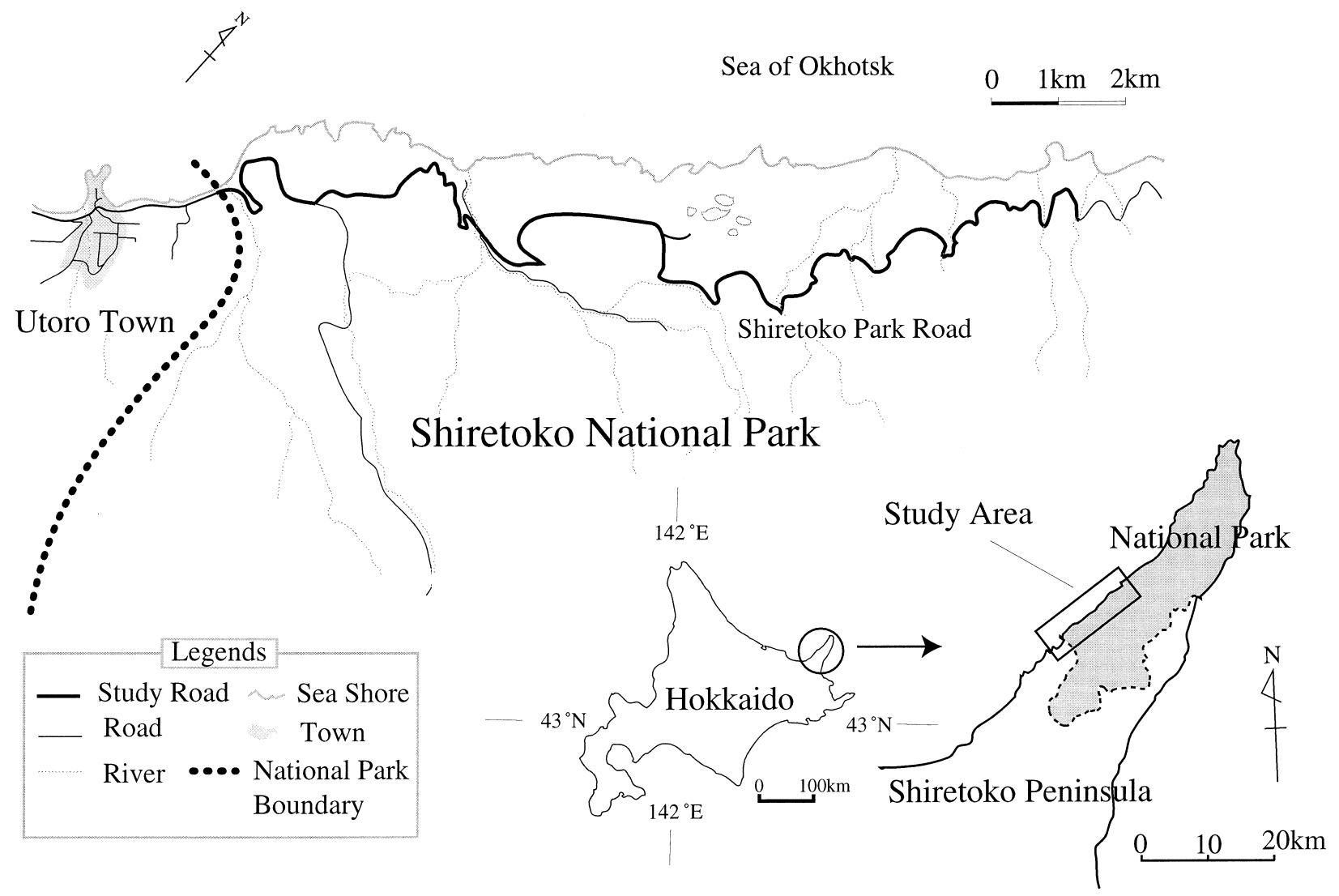

Fig. 1. Map of the study area in the Shiretoko National Park.

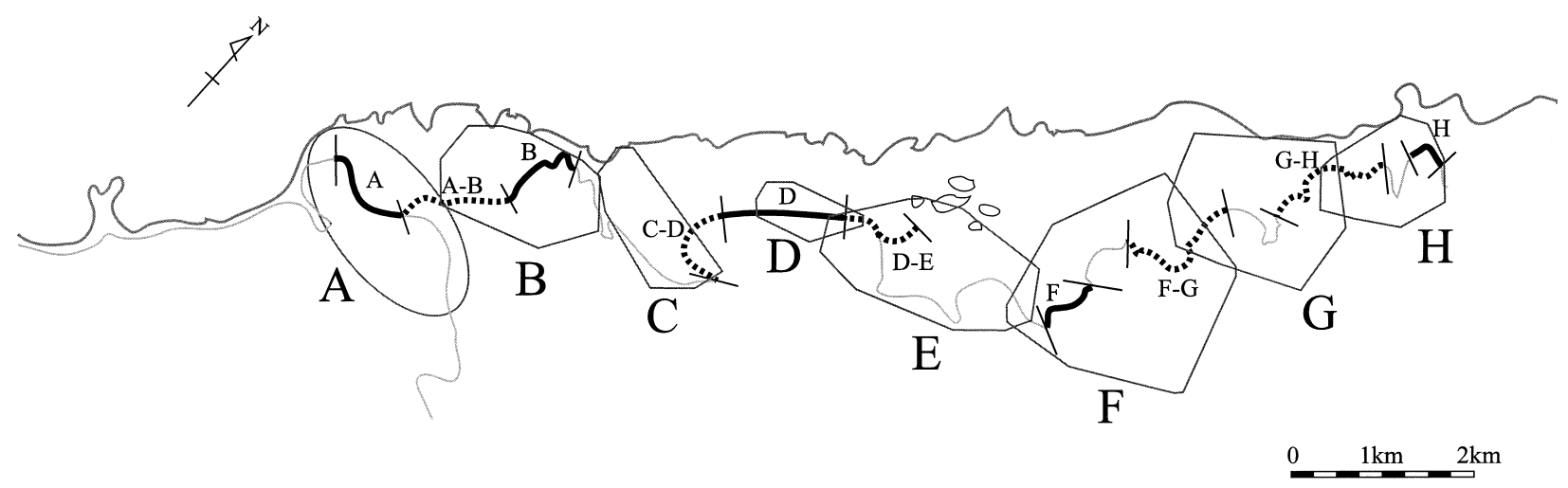

Fig. 2. Territories of 8 fox families (circle or polygon) living along the Shiretoko Park Road. Territories of Family B and $\mathrm{D}$ to $\mathrm{H}$ are drawn by $95 \%$ Minimum Convex Polygons (MCP) of all locations of radio-collared females in reproductive condition from May to August, 1993. Territory of Family C is drawn by $95 \%$ MCP of all locations of a radio-collared male from May to July, 1994. Territory of Family A is roughly drawn from many sightings of its residents. The road belonging to these territories was subclassified to main territory zones of 1 fox family ( - ) and boarder zones of 2 adjacent fox territories $(\cdots)$.

\section{Faecal examination for the parasite eggs}

Parasite egg examination was performed by the sucrose centrifugal flotation technique (Ito, 1980) using a sucrose solution with $1 \cdot 27$ specific gravity.

\section{Statistical analysis}

Correspondency of the results of coproantigen detection assay and faecal egg examination was analysed by $2 \times 2 \chi^{2}$ contingency analysis.

\section{RESULTS}

Assessment of the prevalence of fox families in the study area

The number of fox faeces collected, positive percentage of taeniid eggs and positive percentage of $E$. 

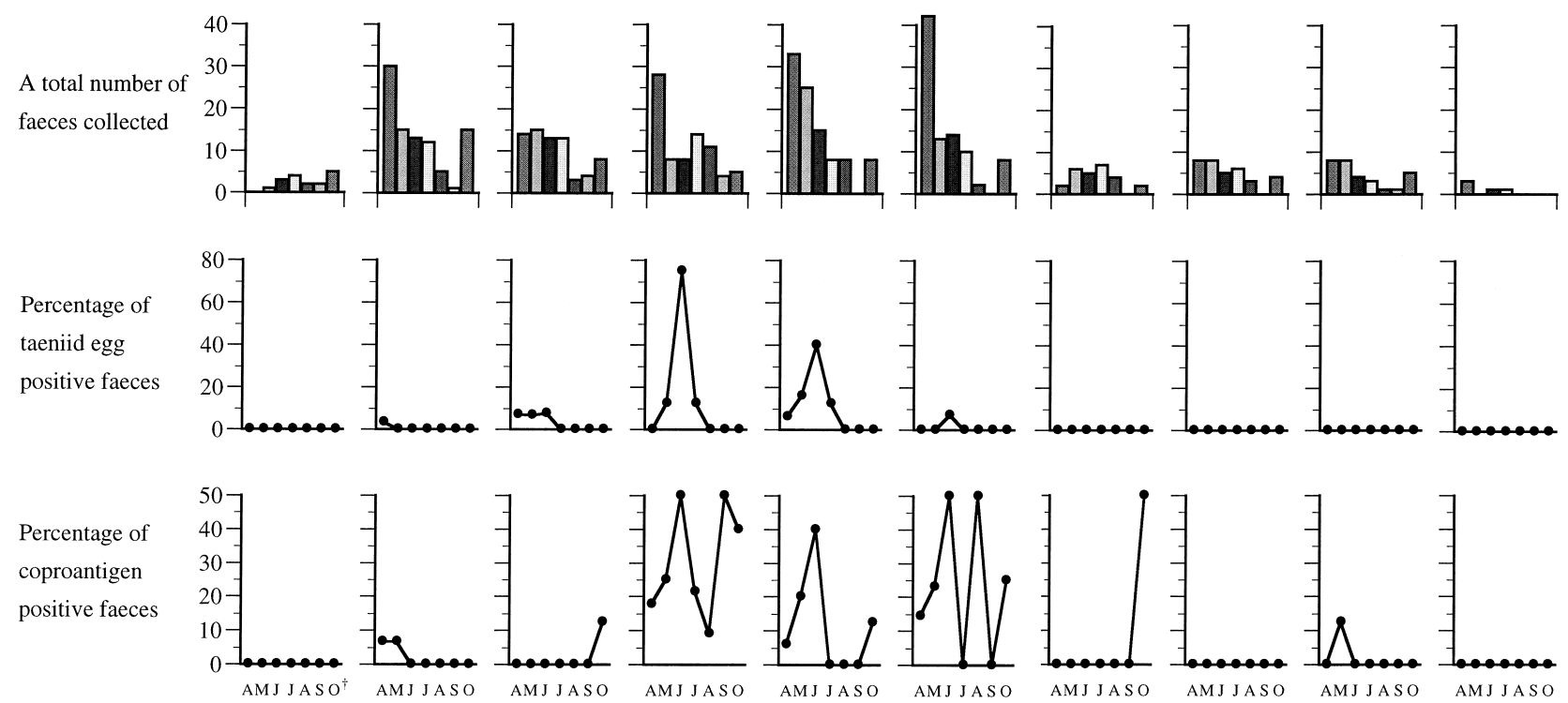

Fig. 3. Change in the number of faeces collected, positive rate for Taeniid eggs and positive rate for Echinococcus multilocularis coproantigen during April to October in 1994 in each territory zone of fox families in the Shiretoko National Park. * Territory zones of Fox Family A to H. 'A-B' indicates the border territory zone of Family A and B. † AMJJASO indicates April, May, June, July, August, September and October.

Table 1. Correspondency* of coproantigen detection assay and sucrose flotation taeniid egg detection assay

\begin{tabular}{lllc}
\hline \hline \multicolumn{3}{c}{ Coproantigen } & \\
\cline { 2 - 3 } & Positive & Negative & Total \\
\hline Taeniid egg & 14 & 13 & 27 \\
$\quad$ Negative & 44 & 466 & 510 \\
Positive & 58 & 479 & 537 \\
Total & 58 & & \\
\hline \hline
\end{tabular}

* $2 \times 2 \chi^{2}$ contingency analysis shows $P<0 \cdot 0001$.

multilocularis coproantigen in each territory zone during the study period are shown in Fig. 3. In total (537 faeces), most were collected in April (168) and fewest in September (12). The spatial distribution of faeces was also clustered and $80.8 \%$ of faeces were obtained at territory zones, A-B, B, C-D, D and D-E. Most of the positive (either egg or coproantigen) faeces were found in territory zones $\mathrm{C}-\mathrm{D}, \mathrm{D}$, and $\mathrm{D}-\mathrm{E}$. In addition, a few positive faeces were also recognized sporadically at other territory zones.

\section{Comparison of the coproantigen detection and the faecal egg examination}

In the total of 537 faeces, 58 were found to be coproantigen positive and 27 were taeniid egg positive. The correspondency of these positive faeces is shown in Table 1. Although contingency analysis shows statistical significance $(P<0.0001)$, inconsistency was observed in the results of the two assays; 44 samples were coproantigen positive but egg negative and 13 samples were coproantigen negative but egg positive.

\section{Assessment of the change in infection status of Family D}

Because most of the positive (either coproantigen or egg) faeces were collected at territory zones related to Family D (zones C-D, D, and D-E), all the data of faeces collected at territory zones $\mathrm{C}-\mathrm{D}, \mathrm{D}$, and $\mathrm{D}-\mathrm{E}$ were combined and the change in infection status of Family D was evaluated. Fig. 4 shows the changes in positive rates of coproantigen detection assay and faecal egg examination in Family D during the study period. Because sample size in September was too small $(n=4)$ for precise evaluation, data for September were omitted from data analysis. In Fig. 4 , data for September are enclosed in parentheses and data for August and October are connected with a dotted line. The positive rate in the coproantigen detection assay showed a peak in June, became low in July and August and increased in October, whereas only 1 peak was observed in faecal egg examination in June. From August to October, egg-positive faeces were not observed. Fig. 5 shows the changes in OD values of the coproantigen detection assay and number of eggs detected by faecal egg examination in the positive faeces of Family D. The OD value of coproantigen detection assay showed higher values from April to June, 
A Number of faeces collected

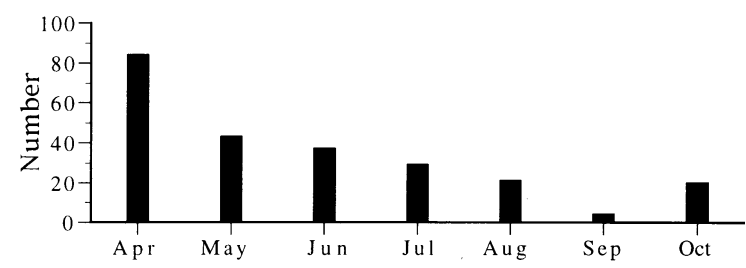

B Coproantigen detection assay

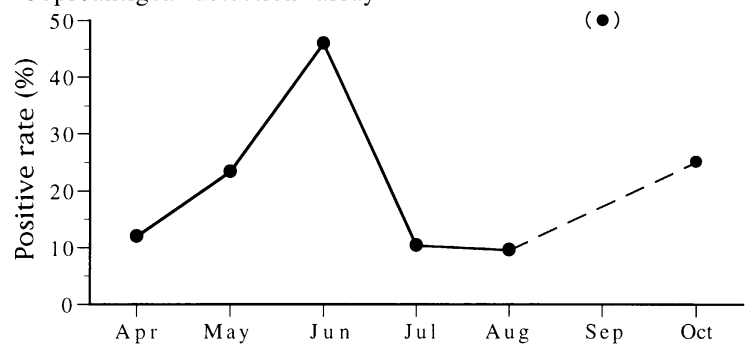

C Faecal egg examination

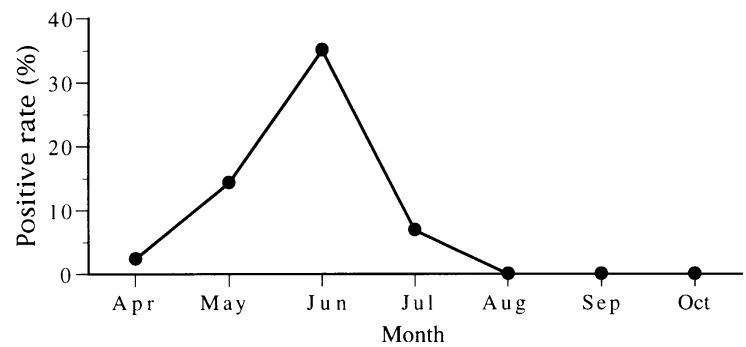

Fig. 4. Change in the positive rate of coproantigen detection assay (B) and faecal egg examination (C) of Family D*. A total number of faeces collected at each month is also shown (A). Because sample size in September was too small $(n=4)$ for precise evaluation, data of September are enclosed in parenthesis and data of August and October are connected with a dotted line. *: Including territory zones $\mathrm{C}-\mathrm{D}, \mathrm{D}$ and $\mathrm{D}-\mathrm{E}$.

lower from July to September and higher again in October. The mean number of eggs detected showed the highest value in April and gradually decreased thereafter. No eggs were detected from August to October.

\section{Examination of the faeces collected around dens}

In June and July, 1 den used by Family A, 2 dens and 1 resting site used by Family D were located. Out of 78 faeces collected around these dens and resting site, only 1 coproantigen-positive faeces was observed in a den of Family D (Table 2). Egg positive faeces were not detected.

\section{Examination of faeces deposited by identified foxes}

In June, faeces of 2 adult females belonging to Family D were collected and examined. Faeces of 1 female were coproantigen and taeniid egg positive but the other was negative for both.
A Coproantigen detection assay

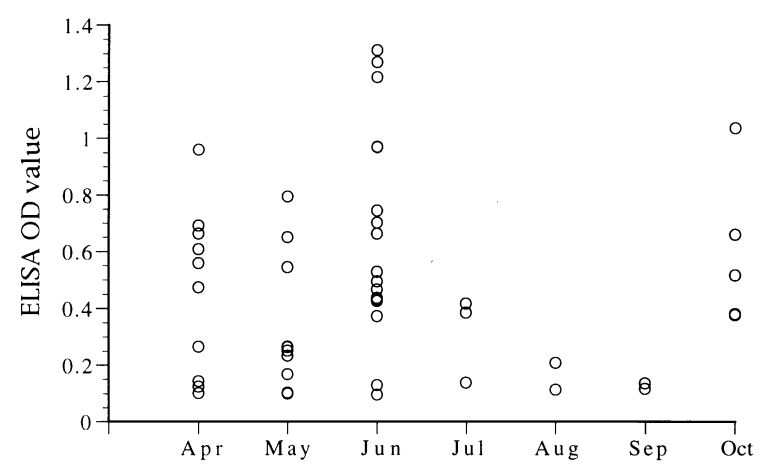

B Faecal egg examination

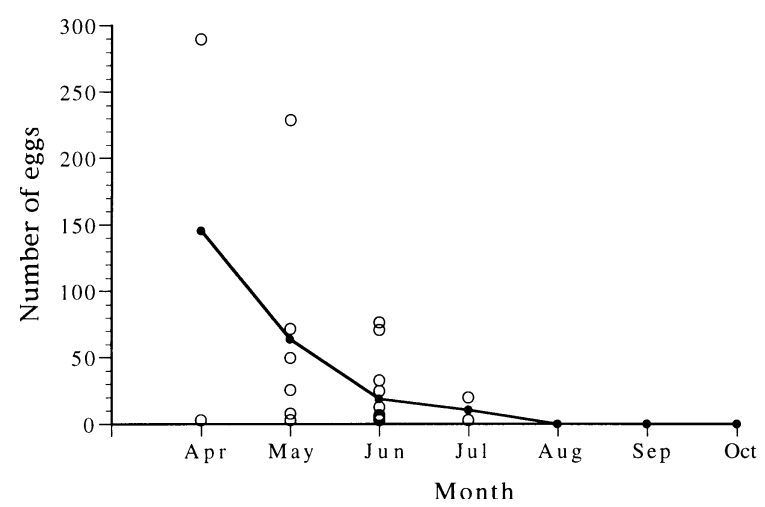

Fig. 5. Change in the OD value of coproantigen detection assay (A) and the number of eggs detected by faecal egg examination (B) in the positive faeces of Family $D^{*}$. ( $\left.\bigcirc\right)$ Individual positive values; $(\bigcirc)$ mean values of the taeniid egg positive in each month. *: Including territory zones C-D, D and D-E.

\section{DISCUSSION}

Echinococcosis in Japan was considered as a local endemic disease in a restricted area of Hokkaido, at least when the parasite was first detected in a small island, Rebun, located at north-west of Hokkaido in 1937 (Ohbayashi, 1996). However, the parasite increased its distribution dramatically in the last 2 decades and, at present, it is recognized all over the Hokkaido (Schantz, Eckert \& Craig, 1996). The prevalence of E. multilocularis infection in red foxes has been also dramatically increased, especially in the last decade. Moreover, red foxes in Hokkaido, along with its population increase, have been frequently seen in tourist areas and in urban areas foraging for food and breeding (Tsukada \& Nonaka, 1996). Under such circumstances, which permit a close contact between red foxes and humans, it is an urgent requirement to establish a control measure for the disease transmission to humans (Kamiya, 1996).

The study area provided a suitable condition for the assessment of infection status of foxes by coproantigen detection assay. First, foxes had their distinct territories in the study area. Foxes were 
Table 2. Examination of faeces collected around fox dens and resting area located during the study period

\begin{tabular}{lllll}
\hline \hline Fox dens & $\begin{array}{l}\text { Month in use } \\
\text { by foxes }\end{array}$ & $\begin{array}{l}\text { Total no. of faeces } \\
\text { collected }\end{array}$ & $\begin{array}{l}\text { Coproantigen } \\
\text { number positive }\end{array}$ & $\begin{array}{l}\text { Taeniid egg } \\
\text { number positive }\end{array}$ \\
\hline Family A & May to August & 26 & 0 & 0 \\
Family D-1 & May to July & 20 & 1 & 0 \\
Family D-2 & June to July & 11 & 0 & 0 \\
Family D-3* & July & 21 & 0 & 0 \\
\hline \hline
\end{tabular}

* Resting site used by Family D.

reported to deposit their faeces throughout their territories like urine marks (Macdonald, 1979). Therefore, faeces collected inside a territory of 1 fox family can be considered as faeces of a fox belonging to the family. Second, it is generally hard to locate the place where fox faeces are deposited. However, fox faeces were easily found along the Park Road in the study area because the foxes were frequently observed along the road and deposited faeces. High variation, however, was recognized in the number of faeces collected in each month. This is because the frequency of foxes appearing on the road decreased in early summer and autumn (Tsukada \& Nonaka, 1996). In addition, the grass on the shoulder of the road was frequently mowed in summer and the foxes faeces disappeared.

The present study shows the usefulness of the coproantigen detection assay in the monitoring or screening for the infection status of red foxes in high risk areas for human-red fox contacts. Because the material required for the assay is faeces, examination can be carried out on live animals with minimum disturbance of their ecology. Moreover, safe manipulation of the assay by heating the faecal materials and inactivating the parasite eggs is advantageous (Nonaka et al. 1996a).

Overall comparison of the coproantigen detection assay with faecal egg examination showed some discrepancy. In all, 44 faecal samples were coproantigen positive but taeniid egg negative. Part of these were assumed to be related to the diagnostic sensitivity (detection limit) of the faecal egg examination assay used. Recovery of eggs from faeces after heat sterilization at $70{ }^{\circ} \mathrm{C}$ for $6-24 \mathrm{~h}$ or after desiccation was observed to be largely reduced (unpublished observation). These may have also included faeces deposited during the pre-patent period or the intermittence of egg excretion in the patent period, both of which have been observed in a fox necropsy survey (Mathis, Deplazes \& Eckert, 1996) and in the experimental infections (Nonaka et al. 1996b; Yagi, Ito \& Ishige, 1996a). Thirteen samples were coproantigen negative but taeniid egg positive. These may indicate the infection of other taeniid cestodes or the low stability of the coproantigen in natural conditions.

A recent study revealed that coproantigen of T.hydatigena, obtained from experimentally infected dogs, showed weak cross-reaction in the coproantigen detection assay used in this study (unpublished data). Despite this observed crossreactivity, infection of Taenia species in foxes has never been reported in Hokkaido. The only report of Taenia infection in Hokkaido is in dogs in which T.pisiformis, T.hydatigena and T.taeniaeformis were found, whereas no Taenia infection was recognized in foxes surveyed at the same time (Yorozuya et al. 1968). Therefore, the prevalence of taeniid cestodes other than E. multilocularis seems to be low in foxes in Hokkaido. Accordingly, the finding of coproantigen or even taeniid eggs in foxes can be considered as E. multilocularis infection. Overall prevalence of $E$. multilocularis infection in foxes in the study area of Shiretoko was found to be low. Only 1 family was assumed to be infected out of 8 families. Coproantigen or egg-positive faeces sporadically found in other family territories may indicate that foxes which were living in those territories but did not frequently appear or deposit faeces along the road were infected, or that infected foxes travelling from other areas deposited their faeces in those areas.

In the fox Family D, both coproantigen and taeniid egg-positive faeces were observed during April to July. Therefore, the infection in this period is patent. However, during August to October, only coproantigen-positive faeces were collected, and taeniid egg-positive faeces were not found. It has been reported that coproantigen can be detected during the pre-patent period and its excretion increased according to parasite development (Deplazes et al. 1992; Nonaka et al. 1996b; Sakai et al. 1996). Since the ELISA OD values of coproantigen detection in October showed an evident increase, the observed infection in October was assumed to be newly acquired. Therefore, those results indicate that Family $\mathrm{D}$ was already infected at the beginning of the study, but the infection became close to cessation in summer and the family acquired new infections in the early autumn. Actually, a faeces collected in June from a fox belonging to Family D was coproantigen and taeniid egg positive.

High variability in individual ELISA OD values of Family D faeces was noted in each month. This may be another indication of low stability of coproantigen in the natural condition. Variability of 
the number of taeniid eggs was also noted in Family D. Irregular excretion of eggs by E. multilocularis has been observed in the experimental infection due to the discrete excretion of eggs (gravid segments) by the cestode (Yagi et al. 1996).

The secondary purpose of this study is to set the pilot area for control of E. multilocularis using praziquantel. A control trial of foxes with praziquantel has been carried out in Germany (Schelling et al. 1997). In the trial, prevalence in foxes was assessed in the core and marginal zones of the trial area by hunting and necropsy. Annual hunting pressure was reported to be $2 \cdot 2$ foxes $/ \mathrm{km}^{2}$, thus the effect of newly invading foxes on the overall prevalence is very large, especially in the marginal zone. Assessment of fox prevalence by coproantigen and egg detection can overcome this problem, although difficulty of locating the fox faeces should be solved. Nevertheless, in tourist locations and some urban areas in Hokkaido, where foxes were seen foraging for food and breeding, coproantigen and egg detection technique would be an ideal tool for evaluating the infection status of the specifically targeted foxes. Moreover, coupling of the PCR-based specific DNA detection technique for E. multilocularis (Mathis et al. 1996; Yagi et al. 1996) will improve the methodological specificity. For setting the pilot area, appropriate infection pressure and prevalence are required to assess the control trial. However, in the study area, faeces collected around the dens and a resting site of Family A and D which were presumably composed of pups' faeces were all coproantigen and taeniid egg negative, except for 1 faeces. This indicates that the infection pressure in the study area was low. Under this circumstance, Family D may have acquired infection twice in 1994, first in late winter and second in late summer or early autumn, because the duration of single infection was found to be limited to several months in foxes (Nonaka et al. 1996b) and dogs (unpublished data). Further study of this area may give us information of the duration of single infections in the natural condition.

In high-risk areas for human-red fox contacts such as touring locations and large parks in urban areas, management of the disease in wildlife is ultimately required, especially if such wildlife is allowed to contact humans. Therefore, in such areas, efforts should be directed to find such 'places', and if such places are located or already known, foxes should be examined for their infection status and dewormed. At present, a large-scale efficient control measure for alveolar echinococcosis has not been established and even the transmission routes to humans have not been completely clarified. Therefore, it is paramount to clarify the individual potential high risk circumstances and establish and apply small-scale efficient management measures immediately. As part of this, a survey of E. multi- locularis prevalence in domestic dogs in Hokkaido is now ongoing in our laboratory using the coproantigen detection assay to clarify the role of domestic dogs in the transmission of $E$. multilocularis to humans, which has been suggested in St Lawrence Island, Alaska (Rausch, 1995), and Gansu and Sichuan, China (Jiang, 1996).

The authors are sincerely grateful to Dr Minoru Taketazu, $\mathrm{Mr}$ Masami Yamanaka, the members of Shiretoko National Park Nature Center and Koshimizu government for their valuable support and suggestions. We also thank the staff of the Laboratory of Parasitology, Graduate School of Veterinary Medicine, Hokkaido University for their intensive support. This study was funded by the Fellowships of the Japan Society for the Promotion of Science for Japanese Junior Scientists, by the Hokkaido Foundation for the Promotion of Scientific and Industrial Technology, by the Ministry of Education, Science and Culture of Japan and by the Ministry of Health and Welfare of Japan.

\section{REFERENCES}

Allan, J. C. \& CRAiG, P. s. (1989). Coproantigens in gut tapeworm infections: Hymenolepis diminuta in rats. Parasitology Research 76, 68-73.

allan, J. C., CRaig, P. S., NOval, J. G., Mencos, F., LiU, D., WANG Y., WEN, H., ZHOU, P., STRINGER, R., ROGAN, M. \& ZEYHLE, E. (1992). Coproantigen detection for immunodiagnosis of echinococcosis and taeniasis in dogs and humans. Parasitology 104, 347-355.

BRETAGNe, s., GUIllou, J. P., MORAND, M. \& HOUIN, R. (1993). Detection of Echinococcus multilocularis DNA in fox faeces using DNA amplification. Parasitology 106, 193-199.

CRAig, P. S., ROGAN, M. T. \& Allan, J. C. (1996).

Detection, screening and community epidemiology of taeniid cestode zoonoses: cystic echinococcosis, alveolar echinococcosis and neurocysticercosis. In Advances in Parasitology (ed. Baker, J. R., Muller, R. \& Rollinson, D.), pp. 169-250. Academic Press, San Diego.

DEPlazes, P., GOTTSTEIN, B., ECKERT, J., JENKins, D. J., EWALD, D. \& Jimenez-PALACios, s. (1992). Detection of Echinococcus coproantigens by enzyme-linked immunosorbent assay in dogs, dingoes and foxes. Parasitology Research 78, 303-308.

Deplazes, P. \& ECKerT, J. (1996). Diagnosis of the Echinococcus multilocularis infection in final hosts. Applied Parasitology 37, 245-252.

FRASER, A. \& CRAIG, P. s. (1997). Detection of gastrointestinal helminth infections using coproantigen and molecular diagnostic approaches. Fournal of Helminthology 71, 103-107.

ITO, s. (1980). Modified Wisconsin sugar centrifugalflotation technique for nematode eggs in bovine faeces. Fournal of Fapan Veterinary Medical Association 33, 424-429.

JIANG, C. P. (1996). Epidemiology of alveolar and cystic echinococcosis in China. In Alveolar Echinococcosis. Strategy for Eradication of Alveolar Echinococcosis of the Liver (ed. Uchino, J. \& Sato, N.), pp. 49-57. Fujishoin, Sapporo. 
КАміYа, м. (1996). Workshop summary:

Zoonosis - environmental transmission as exemplified by echinococcosis. Veterinary Parasitology 64, 149-151.

KOHNO, H., SAKAI, H., OKAMOTO, M., ITO, M., OKU, Y. \& KAMIYA, M. (1995). Development and characterization of murine monoclonal antibodies to Echinococcus multilocularis adult worms and its use for the coproantigen detection. Fapanese Fournal of Parasitology 44, 401-412.

MaCDONALD, D. W. (1979). Some observations and field experiments on the urine marking behaviour. Zeitschrift für Tierpsychologie 51, 1-22.

MACDONALD, D. W. (1980). Patterns of scent marking with urine and faeces amongst carnivore communities. Symposia of the Zoological Society of London 45, 107-139.

Mathis, A., DEPlazes, P. \& ECKERT, J. (1996). An improved test system for PCR-based specific detection of Echinococcus multilocularis eggs. Fournal of Helminthology 70, 219-222.

NONAKA, N., IIDA, M., YAGI, K., SAKAI, H., INOHARA, J., OOI, H. K., OKU, Y. \& KAMIYA, M. (1996a). A diagnostic method for the definitive host of Echinococcus multilocularis by coproantigen detection. In Alveolar Echinococcosis - Strategy for Eradication of Alveolar Echinococcosis of the Liver (ed. Uchino, J. \& Sao, N.), pp. 147-149. Fujishoin, Sapporo.

NONAKA, N., IIDA, M., YAGI, K., ITO, T., OOI, H. K., OKU, Y. \& KamiYA, M. (1996b). Time course of coproantigern excretion in Echinococcus multilocularis infections in foxes and an alternative definitive host, golden hamsters. International Fournal for Parasitology 26, 1271-1278.

ohbayashi, M. (1996). Host animals of Echinococcus multilocularis in Hokkaido. In Alveolar Echinococcosis. Strategy for Eradication of Alveolar Echinococcosis of the Liver (ed. Uchino, J. \& Sato, N.), pp. 59-64. Fujishoin, Sapporo.

RAUSCH, R. L. (1995). Life-cycle patterns and geographic distribution of Echinococcus species. In Echinococcus and Hydatid Disease (ed. Thompson, R. C. A. \& Lymbery, A. J.), pp. 89-134. CAB International, Wallingford.

SAKai, H., FURUSAWA, R., OKU, Y. \& KAMIYA, M. (1996). Echinococcus multilocularis coproantigen detection in golden hamster, an alternative definitive host.

Experimental Animals 45, 275-278.

SAKai, H., MALGOR, R., BASMAdJiAN, I., GALlaRdo, R., CARMONA, C., SATO, H., OKU, Y. \& KAMIYA, M. (1995). An enzyme-linked immunosorbent assay (ELISA) for the detection of Echinococcus granulosus coproantigens in dogs. Fapanese Fournal of Parasitology 44, 453-461.
SAKASHITA, M., SAKAI, H., KOHNO, H., OOI, H. K., OKU, Y., ITO, M. \& KAMIYA, M. (1995). Detection of Echinococcus multilocularis coproantigens in experimentally infected dogs using murine monoclonal antibody against adult worms. Fapanese Fournal of Parasitology 44, 413-420.

SCHANTZ, P. M., ECKERT, J. \& CRAIG, P. s. (1996).

Geographic distribution, epidemiology, and control of Echinococcus multilocularis and alveolar echinococcosis. In Alveolar Echinococcosis - Strategy for Eradication of Alveolar Echinococcosis of the Liver (ed. Uchino, J. \& Sao, N.), pp. 1-25. Fujishoin, Sapporo.

SCHELling, U., FRANK, W., WILl, R., ROMIG, T. \& LUCIUS, R. (1997). Chemotherapy with praziquantel has the potential to reduce the prevalence of Echinococcus multilocularis in wild foxes (Vulpes vulpes). Annals of Tropical Medicine and Parasitology 91, 179-186.

TSUKADA, H. (1994). A study of the ecology of foxes in Shiretoko National Park and their utilization for nature education programs. Bulletin of Shiretoko Museum 15, 63-82. (In Japanese with English summary.)

TSUKADA, H. (1995). The effect of the feeding by tourists on the foraging behavior of the red fox in Shiretoko National Park. Concentrating on the food begging behaviour of the foxes. Bulletin of Shiretoko Museum 16, 1-9. (In Japanese with English summary.)

TSUKADA, H. (1997). A division between foraging range and territory related to food distribution in the red fox. Fournal of Ethology 15, 27-37.

TSUKADA, H. \& NONAKA, N. (1997). Foraging behaviour of red foxes (Vulpes vulpes schrencki) utilizing human food in the Shiretoko National Park. Mammal Study 21, 137-151.

YAGI, K., ITO, T. \& ISHIGE, M. (1996a). A survival strategy of Echinococcus multilocularis presumed by experimental studies. In Alveolar Echinococcosis Strategy for Eradication of Alveolar Echinococcosis of the Liver (ed. Uchino, J. \& Sao, N.), pp. 97-99. Fujishoin, Sapporo.

yagi, K., OHyama, T., OKamoto, M., KUrosaWa, T. \& KAMiYa, M. $(1996 b)$. The application of PCR for the identification of Echinococcus multilocularis in Hokkaido. In Alveolar Echinococcosis - Strategy for Eradication of Alveolar Echinococcosis of the Liver (ed. Uchino, J. \& Sao, N.), pp. 165-170. Fujishoin, Sapporo.

yorozUYa, K., KoSAKa, T., ICHIKAWA, A., SATO, T. \& IDA, T. (1968). Epizootiologial consideration on multilocular echinococcosis in eastern Hokkaido, Japan. Fournal of Japan Veterinary Medical Association 21, 471-476. (In Japanese with English summary.) 